\title{
Experimental Investigation of Tensile Strength and Deflection Characteristics of Friction Stir Welded Aluminum AA 6351 Alloy Joint
}

\author{
G.Gopala Krishna ${ }^{1}$, P.Ram Reddy ${ }^{2}$ and M.Manzoor Hussain ${ }^{3}$ \\ ${ }^{I}$ Associate Professor, J.B. Institute of Engineering \& Technology, Hyderabad, Andhra Pradesh, India, \\ ${ }^{2}$ Director, Malla Reddy College of Engineering \& Technology, Hyderabad, \\ ${ }^{3}$ Principal, JNTUH College of Engineering, Sulthanpur, Medak District, Andhra Pradesh, India.
}

\begin{abstract}
Aluminum alloys are used in many applications in which the combination of high strength and low weight is attractive; ship building, air frame, transportation industry etc. are some areas in which the low weight can be significant value. Friction stir welding $(F S W)$ is a new welding technique particularly well suited to aluminum alloys though this technique is also used for other materials. Friction stir welding promises joints with low porosity, fine microstructures, minimum phase transformation and low oxidation compared to conventional welding techniques. It is capable of joining combinations of alloys not amenable to conventional welding.Experiments for tensile and deflection tests were carried out and reported in this research paper. The base material used for friction stir welding was AA 6351-T4 Aluminum alloy. Tensile strength and breaking loads were increased with increase of rotational speed of the tool but it drops after attaining marginal speed. Deflections of friction stir welded specimens and base materials were compared and they exhibited almost similar trends at different load conditions and deflections of all the specimens were increased with increment of load.
\end{abstract}

Keywords - Friction Stir Welding (FSW), Aluminum AA 6351 alloy, tensile strength, breaking load and deflection.

\section{INTRODUCTION}

Friction stir welding (FSW) [1] is a solid state joining process (i.e., the metal is not melted during the process) developed and patented by The Welding Institute (TWI), UK in 1991, emerged as a new welding technique to be used in high strength alloys that are difficult to join with conventional welding techniques. The process was initially developed for Aluminum alloys but since then FSW was suitable for joining large number of other materials [2]. Conventional fusion welding of Aluminum alloys often produce a weld which suffers from defects, such as porosity developed as a consequence of entrapped gas not being able to escape from the weld pool during solidification process. In contrast, with FSW the interaction of non consumable rotating tool traversing along the joint line creates a welding joint through plastic deformation and consequent heat dissipation resulting temperatures below the melting point of the materials being joined. Other interesting benefits of FSW compared to fusion welding processes are low distortion, excellent mechanical properties in the weld zone, execution without a shielding gas and suitability to weld all Aluminum alloys [3].

FSW can be used to produce Lap, Butt, Corner, T, Spot, Fillet and Hem joints, as well as to weld hollow objects, such as tanks and tubes/pipes, stock with different thicknesses, tapered sections and parts with 3dimensional contours $[2 \& 4]$. The technique can produce joints utilizing equipment based on traditional machine tool technologies, and it has been used to weld a variety of similar and dissimilar alloys along with welding metal matrix composites and to repair existing joints. Replacement of fastened joints with FSW joints can lead to significant weight and cost savings, attractive propositions for many industries [5].

The basic principle of friction stir welding process is remarkable simple. A rotating tool with pin and shoulder is inserted in the material to be joined and traversed along the joint line. The heating is localized and generated by friction between the rotating tool and work piece, with additional adiabatic heating from metal deformation [6-7]. The pin and shoulder of the tool can be modified in number of ways to influence material flow and micro structural formation. Friction welding process is shown in following figure 1. 


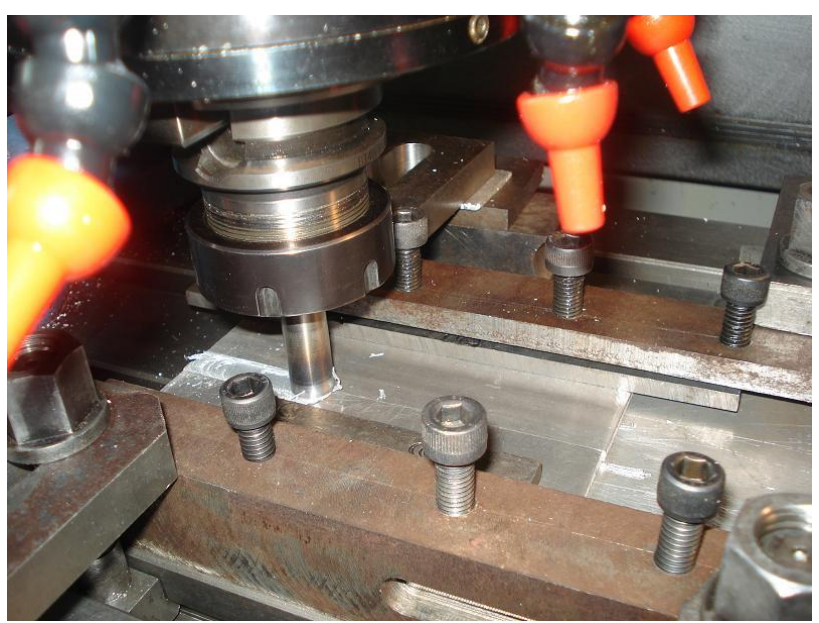

Fig.1. FSW Experimental setup

\subsection{Material}

\section{Experimental procedure}

The material used for this research study is AA 6351- T4 Aluminum alloy of $150 \mathrm{~mm}$ in length, $60 \mathrm{~mm}$ in width and $4 \mathrm{~mm}$ in thickness. The standard and experimental chemical compositions are listed in Table.1. Mechanical and Physical properties also presented in table. 2 \& table. 3 respectively.

Table.1 Chemical composition (\%)

\begin{tabular}{|l|l|l|}
\hline \multirow{2}{*}{ Element } & AA 6351- T4 \\
\cline { 2 - 3 } & Standard & Experimental \\
\hline $\mathrm{Si}$ & $0.07-1.3$ & 0.93 \\
\hline $\mathrm{Fe}$ & 0.5 & 0.36 \\
\hline $\mathrm{Cu}$ & 0.1 & 0.1 \\
\hline $\mathrm{Mn}$ & $0.4-0.8$ & 0.57 \\
\hline $\mathrm{Mg}$ & $0.4-0.8$ & 0.55 \\
\hline $\mathrm{Zn}$ & 0.2 & 0.134 \\
\hline $\mathrm{Ti}$ & 0.2 & 0.014 \\
\hline $\mathrm{Al}$ & Remaining & Remaining \\
\hline
\end{tabular}

Table.2 Mechanical Properties

\begin{tabular}{|l|l|}
\hline Brinell Hardness & 67 \\
\hline Knoop Hardness & 90 \\
\hline Vickers Hardness & 77 \\
\hline Ultimate Tensile Strength & $248 \mathrm{MPa}$ \\
\hline Yield Tensile Strength & $152 \mathrm{MPa}$ \\
\hline Elongation at Break & $20 \%$ \\
\hline Modulus of Elasticity & $68.9 \mathrm{GPa}$ \\
\hline Poissions Ratio & 0.33 \\
\hline Shear Modulus & $26 \mathrm{GPa}$ \\
\hline Shear Strength & $150 \mathrm{MPa}$ \\
\hline
\end{tabular}

Table.3 Physical Properties

\begin{tabular}{|l|l|}
\hline Density & $2.71 \mathrm{~g} / \mathrm{cm}^{3}$ \\
\hline Melting Point & $555^{\circ} \mathrm{C}$ \\
\hline Electrical Receptivity & $0.038 \times 10^{-6} \Omega . \mathrm{m}$ \\
\hline Thermal Conductivity & $172 \mathrm{~W} / \mathrm{m} . \mathrm{K}$ \\
\hline Thermal Expansion & $46 \times 10^{-6} / \mathrm{K}$ \\
\hline
\end{tabular}

Aluminum 6351 alloy is a medium strength alloy with excellent corrosion resistance. It has higher strength amongst the 6000 series alloys. Alloy 6351 is known as a structural alloy, in plate form. This alloy is most commonly used for machining. Though relatively a new alloy the higher strength of 6351 has replaced 6061 alloy in many applications. The addition of large amount of Manganese controls the grain structure which in turn results in a stronger alloy. It is difficult to produce thin walled and complicated extrusion shapes as the 
extruded surface finish is not smooth as other similar strength alloys in the 6000 series. Aluminum AA6351-T4 alloys are solution heat-treated and naturally aged to a substantially stable condition.

\subsection{Welding Procedure}

A vertical axis CNC milling machine (Specifications of CNC Milling Machine: Vertical Axes CNC 3Axes Machining Center, Model: BME-45, Spindle Range: 10-6000 rpm, Tool Material: HSS, Movement: 610 X $450 \mathrm{~mm}$ and Bed size: $800 \times 500 \mathrm{~mm}$ ) is converted into a Friction Stir Welding (FSW) machine with an attachment of work holding fixture to weld.

The two work pieces to be welded, with square mating edges, are clamped on a rigid back plate. The fixture prevents the work pieces from spreading apart or lifting during welding process. The welding tool, consisting of a shank, shoulder and pin is then rotated to a specified speed and oriented normal with respect to the work piece. The tool is slowly plunged into the work piece material at the butt line, until the shoulder of the tool forcibly contacts the upper surface of the material and the pin is a short distance from the back plate. A downward force is applied to maintain the contact and a short dwell time is observed to allow for the development of the thermal fields for preheating and softening the material along the joint line. At this point, a lateral force is applied in the direction of welding (travel direction) and the tool is forcibly traversed along the butt line, until it reaches the end of the weld. Upon reaching the end of the weld, the tool is withdrawn, while it is still being rotated. As the pin is withdrawn, it leaves a keyhole at the end of the weld. Friction stir welding was used to control local properties in structural metals including aluminum and other nonferrous and ferrous alloys. The pin may have a diameter one-third of the cylindrical tool and typically has a length slightly less than the thickness of the work piece. The pin is forced or plunged into the work piece until the shoulder contacts the surface of the work piece. As the tool descends further, its shoulder surface touches the top surface of the work piece and creates heat. As the temperature of the material under the tool shoulder elevates, the strength of the material decreases.

\subsection{Tensile Testing}

The tensile tests were conducted to determine the breaking load and yield strength of Aluminum AA6351 alloy friction stir weldments at different rotational speed of the tool in a Universal Testing Machine (UTM) as per ASTM standards.

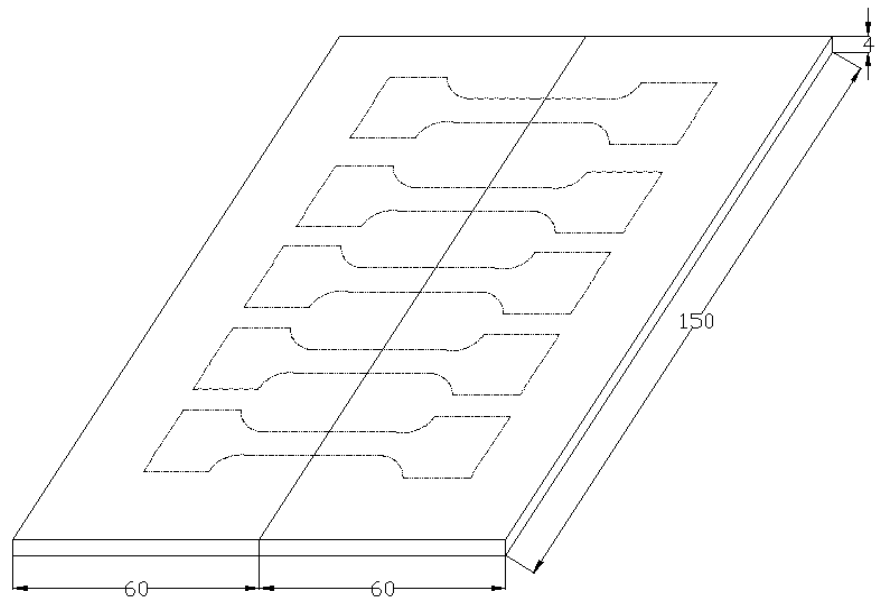

Fig.2. Extraction of tensile specimen from welding piece.

\subsection{Deflection Testing}

Friction stir welded specimen welded at $950 \mathrm{rpm}$ of size $150 \mathrm{~mm}$ length, $60 \mathrm{~mm}$ width and $4 \mathrm{~mm}$ thickness is cut into three specimen pieces of $80 \mathrm{~mm}$ length, $25 \mathrm{~mm}$ width and $4 \mathrm{~mm}$ thickness. The above FSW specimens along with a base material specimen (non friction stir welded) were used in deflection tests by considering cantilever type (by taking one end fixed and other end free by applying load at free end as shown in fig. 4). By increasing load incrementally deflections are calculated and compared between FSW specimens and base material specimen. 


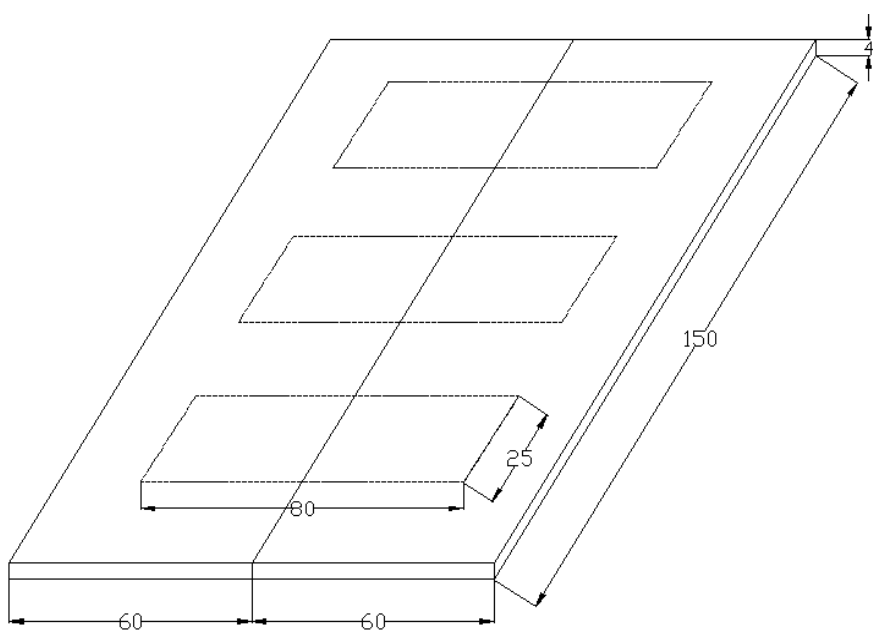

Fig.3. Extraction of deflection specimen from welding piece.

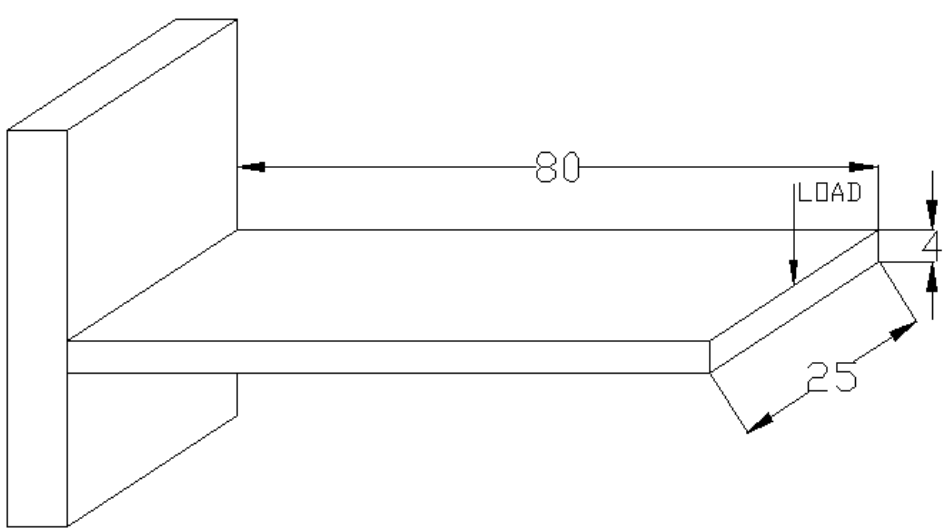

Fig. 4. Cantilever deflection specimen with applied load.

\subsection{Tensile Test Observations}

\section{Results and Discussions}

The Tensile test is conducted on the AA 6351 friction stir weldments in a Universal Testing Machine as per ASTM standards to determine the breaking load and yield strength of the weldment. The obtained results are observed and analyzed by plotting graphs for the rotational speed of the tool Vs breaking load and rotational speed of the tool Vs tensile strength.

The breaking load and tensile strength of all the FSW specimens were lower than that of the base material specimens irrespective of the rotational speeds used to fabricate the joints. At rotational speed of 950 rpm maximum breaking load and maximum tensile strength were observed. The effect of tool rotational speed on tensile strength and breaking load are shown in Figures 5\&6. At lower rotational speed $(850 \mathrm{rpm})$ of the tool, lower tensile strength and breaking load were observed. When the rotational speed is increased from $850 \mathrm{rpm}$ onwards the tensile strength and breaking load are also increased and reach to a maximum value at $950 \mathrm{rpm}$. If the rotational speed is increased more than $950 \mathrm{rpm}$, a reverse trend has been observed i.e. the tensile strength and breaking load has decreased. 


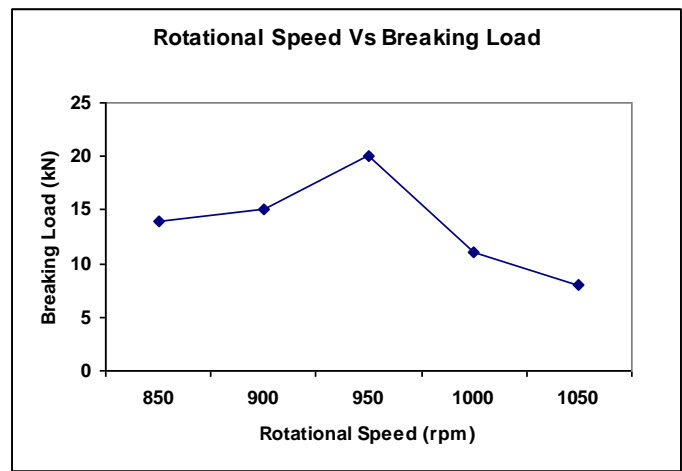

Fig.5. Rotational Speed Vs Breaking Load.

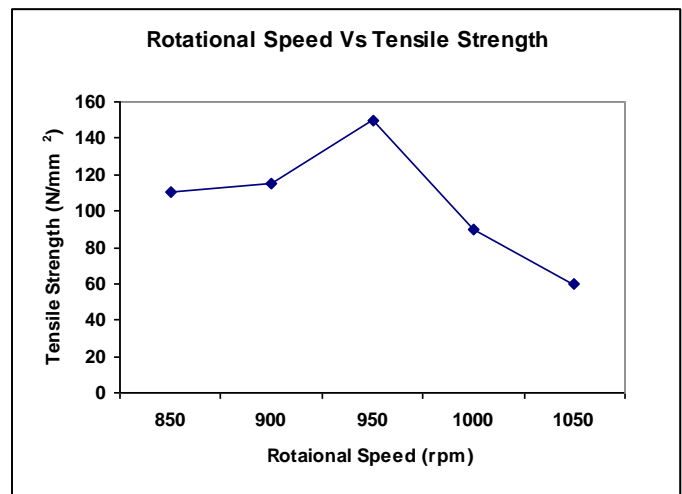

Fig.6. Rotational Speed Vs Tensile Strength.

\subsection{Deflection Test Observations}

Friction stir welded specimen of size $150 \mathrm{~mm}$ length, $60 \mathrm{~mm}$ width and $4 \mathrm{~mm}$ thickness has been cut into three specimens of $80 \mathrm{~mm}$ length, $25 \mathrm{~mm}$ width and $4 \mathrm{~mm}$ thickness. The above FSW specimens along with a base material specimen were used in the cantilever type deflection test.

From fig.7 it is clear that, base material deflection is slightly higher than the other three FSW specimens at $3 \mathrm{~N}$ load but at $6 \mathrm{~N}$ load the base material deflections coinciding with all other three FSW specimens. From $9 \mathrm{~N}$ load onwards friction stir welded specimen No.3, deflections show slightly better results than the base material and other two FSW specimens. Overall FSW and base material specimens deflection have exhibited almost the same trend for all the applied loads. It can be inferred that by using friction stir welding technique for Aluminum alloys deflection values are observed to be same as the base material (non FSW).

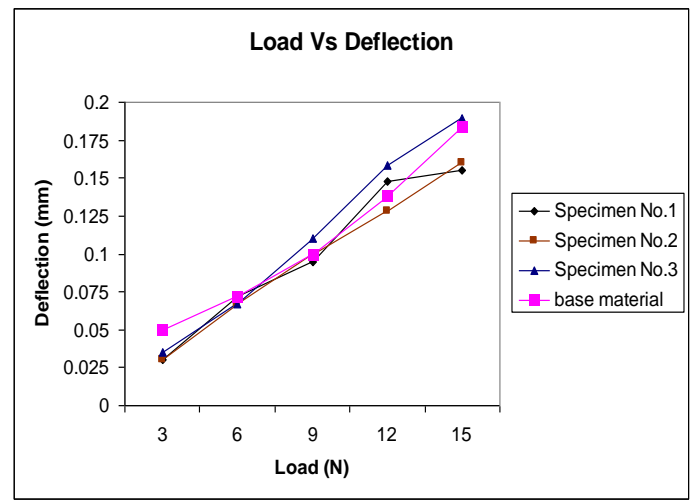

Fig.7. Comparison of friction stir welded specimens with base material (Load Vs Deflection)

\section{Conclusions}

- The joints welded with rotational speed of $950 \mathrm{rpm}$ exhibited superior tensile strength and breaking load compared to other joints.

- Deflections of the FSW specimens and base material specimen are increasing with increase of applied load. All the FSW specimens and base material specimen have shown same results at different load conditions. 


\section{References}

[1] Thomas WM, Nicholas ED, Needham JC, Murch MG, Templesmith P, Dawes CJ, WO/1993/010935, International Patent Number PCT PCT/GB92/02203, TWI, Improvements relating to friction welding; 1992.

[2] Nandan R, DebRoy T and Bhadshia HKDH, Recent advances in friction stir welding - process, weldment structure and properties, Progress in Material Science 53 (2008) 980-1023.

[3] Mishra RM, Mahoney MW, Friction stir welding and processing, ASM Int; 2007

[4] Terry Khaleed, An outsider looks at friction stir welding, ANM-112N-05-06 (July 2005).

[5] Williams SW, Air Space Eur 2001; 3 (3-4):64.

[6] Dawes J, An introduction to friction stir welding and its development, Welding \& Me \& 1 Fab, January, 1995 , P-12.

[7] Liu G, L.E.Murr, Niou CS, McClure JC and Vega FR, Microstructural aspects of the friction stir welding of 6061 - T6 Aluminum, Scripta Materialia, Volume 37, Issue 3, 1 August 1997, Pages 355-361.

[8] L.Ceschini, I Boromei, G.Minak, A.Morri, F.Tarterini, Microstructure, tensile and fatigue properties of $\mathrm{AA} 6061 / 20 \mathrm{Vol} \% \mathrm{Al}_{2} \mathrm{O}_{3} \mathrm{P}$ friction stir welded joints, Journal of Composites, Applied Science and Engineering, Apr 2006, pp 1200 - 1210.

[9] A.KShukla, W.A.Baeslack III, Study of Microstuctural Evolution in Friction-Stir welded thin sheet Al-Cu-Li alloy using transmission -electron microscopy, Journal of Science Direct, Jan 2007, pp 513 - 516. 